\title{
Pulmonary embolism after coronary angiography with femoral approach
}

\author{
Nino Kunac*, Hrvojka Marija Zeljko, Ivica Premužić Meštrović, Tomislav Letilović, Darko Počanić,
} Stjepan Kranjčević, Damir Kozmar

Merkur University Hospital, Zagreb, Croatia

Objectives: Pulmonary embolism after elective coronary angiography is a very rare complication. Herein we report on a case of pulmonary embolism after diagnostic coronary angiography with femoral approach, and we also evaluate various pathophysiologic mechanisms possibly contributing to local vascular complications and also consequently safer and more efficient approaches for percutaneous coronary procedures.

Case report: A 66 year-old female patient was admitted to our department for diagnostic coronary angiography due to high clinical suspicion for coronary artery disease. Coronary angiography was performed with the right common femoral artery access, and no coronary artery stenosis was verified on the examination. Although all the standard postangiography procedures were applied and hemostasis completed, subsequently an access site hematoma and a pseudoaneurysm developed. The day after the procedure, during verticalization, the patient complained of malaise, nausea and vertigo, and due to a high level of D-dimers, we performed MSCT angiography which confirmed pulmonary embolism (Figure 1). The doppler ultrasound of the lower extremity veins showed no signs of deep venous thrombosis, and we have not discovered any predisposing factors for pulmonary embolism.

Discussion: Pulmonary embolism is rarely reported as a consequence of coronary angiography with femoral approach, probably since it is underdiagnosed considering its frequent asymptomatic course. Predisposing factors for deep venous thrombosis and pulmonary embolism with the femoral approach for coronary angiography are manual compression of the puncture site with unintentional compression of the femoral vein, compression with the sandbag and a gauze, puncture site hematoma or a femoral artery pseudoaneurysm, along with prolonged immobilization and bed rest.

Conclusion: We assume that the cause of pulmonary embolism in our patient was transient deep venous thrombosis due to a combination of puncture area compression, hematoma and a femoral pseudoaneurysm with immobilization and postprocedural bed rest. Optimal placement of the arterial sheath, use of smaller sheaths, careful manual compression with shorter period of immobilization and bed rest, can significantly contribute to reducing the incidence of deep venous thrombosis and pulmonary embolism.

KEYWORDS: coronary angiography, pulmonary embolism, deep venous thrombosis.

CITATION: Cardiol Croat. 2013;8(9):286.

\section{Received: $30^{\text {th }}$ May 2013}

*Address for correspondence: Klinička bolnica Merkur, Zajčeva 19, HR-10000 Zagreb, Croatia.

Phone: +385-91-9109-470

E-mail: kunac.nino@gmail.com

Figure 1. Arrow showing the filling defect in the left pulmonary artery for the upper lung lobe indicating pulmonary embolism.

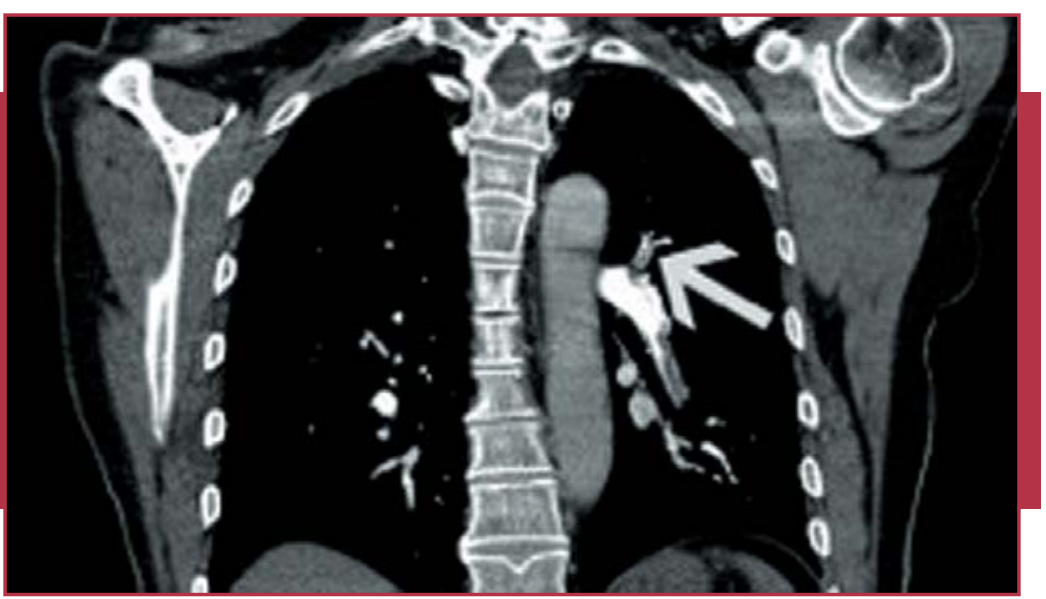

\section{Literature}

1. Tavakol M, Ashraf S, Brener SJ. Risks and complications of coronary angiography: a comprehensive review. Glob J Health Sci. 2012;4:65-93.

2. Shammas RL, Reeves WC, Mehta PM. Deep venous thrombosis and pulmonary embolism following cardiac catheterization. Cathet Cardiovasc Diagn. 1993;30:223-6.

3. Bangalore S, Bhatt DL. Femoral arterial access and closure. Circulation. 2011;124:e147-56. 